\title{
PHOTOCHEMISTRY AND CHARGE TRANSFER CHEMISTRY OF THE PLATINUM GROUP ELEMENTS
}

\section{PEOWIVDD}

Summary Progress Report

MAY O 31003

for Period May 1, 1990 - April 30, 1993

Richard Eisenberg

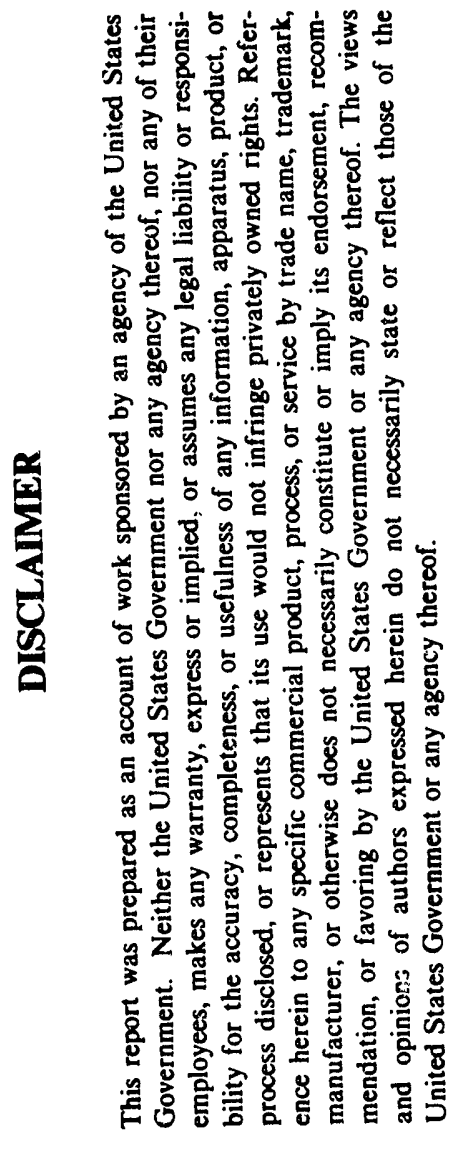

University of Rochester

Rochester, New York 14627

December, 1992

Prepared for

THE U. S. DEPARTMENT OF ENERGY

AGREEMENT NO. DE-FG02-90ER14125 


\section{SUMMARY OF PROGRESS}

An essential aspect of the development of transition metal photochemistry is the discovery of new transition metal complexes possessing emissive excited states. The present research program, which was initiated in 1990 with DOE support, focuses on that aspect, and in particular the photochemistry and photophysics of dithiolate complexes of the platinum group elements. The systems that have been investigated under the current contract are for the most part square planar complexes of $\mathrm{Pt}(\mathrm{II})$ containing one dithiolate chelate and a second chelating ligand or two monodentate ligands to complete the coordination sphere. Prior to commencement of the contract, several complexes containing a diimine chelate in addition to the dithiolate had been synthesized and found to exhibit luminescence in fluid solution. ${ }^{1}$ These initial complexes are shown generically as 1 and 2 with the diimine being bipyridine (bpy), o-phenanthroline (phen) or an alkyl substituted derivative. For $\mathbf{1}$ the dithiolate is maleonitrile dithiolate (mnt) and for $\mathbf{2}$ it is ethyl-2cyano-3,3-dithiolatoacrylate (ecda).<smiles></smiles>

1

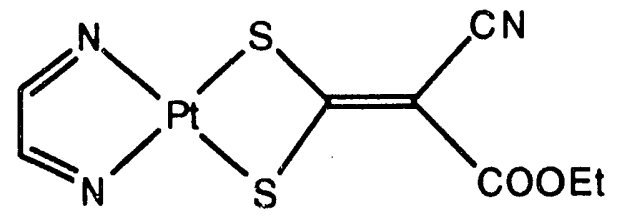

2

$$
\begin{aligned}
\text { diimine }= & \text { (a) } 2,2^{\prime} \text {-bipyridine (bpy) } \\
& \text { (b) } 0 \text {-phenanthroline (phen) } \\
& \text { (c) } 4,4^{\prime}-\mathrm{Me}_{2} \text { bpy } \\
& \text { (d) } 4,4^{\prime}-\mathrm{Ph}_{2} \text { bpy } \\
& \text { (e) } 4,7-\mathrm{Ph}_{2} \text { phen }
\end{aligned}
$$

Complexes of types 1 and $\mathbf{2}$ were observed to have a highly solvatochromic band in the 400-500 nm region of their absorption spectra. Electrochemically, the complexes each showed two reversible reductions and an irreversible oxidation, and in the presence of electron donors or acceptors, the emission of the complexes in fluid solution was quenched. Other studies prior to the 
start of the current contract involved anionic mnt complexes of iridium(I) and rhodium(I) which were emissive only in rigid media $^{2}$ and six-coordinate alkyl mnt complexes of Ir(III) which were among the first solution-emissive organometallic compounds. ${ }^{3}$

During the past three years, considerable progress has been made in elucidating the excited state structures of $\mathrm{Pt}$ (diimine)(dithiolate) complexes shown as 1 and 2 , while more recent efforts have focused on the photochemistry of these complexes and electronic structural properties of other dithiolate systems.

Solvatochromism. The position of the solvent dependent band in the absorption spectra of complexes 1 and $\mathbf{2}$ was found to correlate linearly with solvent polarity scales based on charge transfer transitions such as those of Lees and Dong. ${ }^{4}$ Through systematic ligand variation in which the unsaturated dithiolate was replaced by a saturated dithiolate, bis(thiolates), bis(selenolates) and di(chloride), and the diimine was replaced by di(phosphines), diolefins and the saturated ligand cyclohexanediamine (dach), we found that the intense solvatochromic band ( $\varepsilon$ $\sim 10,000-15,000 \mathrm{M}^{-1} \mathrm{~cm}^{-1}$ ) was present in diimine-containing systerns only and that solvent sensitivity of the band's position was greatly diminished if chloride replaced the chalcogenide donors. Thus the band was assigned to a charge transfer transition between an orbital of $\mathrm{Pt} d$ and $\mathrm{S} p$ character to a $\pi^{*}$ orbital of the diimine ligand. This assignment was consistent with those proposed by Dance, Vogler and Crosby for related systems, 5 although differing in the extent of metal atom participation in the transition. Our conclusions are supported by extended Huckel molecular orbital calculations which we have performed as outlined below.

More recently we have found that replacement of the dithiolate by the oxygen donor chelating agent 3,5-di(t-butyl) catecholate leads to complexes with even greater solvatochromism, supporting the notion that the solvent dependent charge transfer transition is of an inter-ligand type. The fact that the inter-ligand charge transfer transition in square planar complexes is necessarily directional makes these systems of interest in terms of their excited state dipole moments and non-linear optical properties. In this vein, Dr. L.-T. Cheng of DuPont has 2 performed EFISH measurements on some of these Pt(diimine)(dithiolate) systems to determine 
- molecular hyperpolarizabilities $\beta$ and ground state dipole moments. The results, given in Table I, show that the complexes possess NLO responses similar to or greater than those of some organic compounds used as second harmonic generation (SHG) standards, but well below those of best organic dyes now known. 6

Table I

Dipole Moments ( $\mu$ ) and Molecular Hyperpolarizabilities ( $($ ) of Selected Complexes ${ }^{a}$

\begin{tabular}{lcc}
\multicolumn{1}{c}{ Complex } & $\mu(\mathrm{D})$ & $\beta\left(\times 10^{30}\right.$ esu $)$ \\
$\mathrm{Pt}\left(\mathrm{Ph}_{2}\right.$ phen $)(\mathrm{tbcda})^{\mathrm{b}}$ & $9 \pm 1$ & $-15 \pm 2$ \\
$\mathrm{Pt}\left(\mathrm{Ph}_{2}\right.$ phen $)(\text { mncda })^{\mathrm{b}}$ & $7 \pm 1$ & $-7 \pm 2$ \\
$\mathrm{Pt}\left(\mathrm{Ph}_{2}\right.$ phen $)(\mathrm{edt})^{\mathrm{b}}$ & $9 \pm 1$ & $-17 \pm 2$ \\
$\mathrm{Pt}\left(\mathrm{Ph}_{2}\right.$ phen $)\left(p-\mathrm{SC}_{6} \mathrm{H}_{4} \mathrm{NH}_{2}\right)_{2}$ & $10 \pm 1$ & $-39 \pm 8$ \\
nitroaniline & 6.2 & 9.2
\end{tabular}

aMeasurements done using EFSIH method by L.-T. Cheng, DuPont.

btbcda and mncda are the t-butyl and menthyl analogs of ecda, respectively, and edt is ethane-1,2-dithiolate.

Emission Spectroscopy. The emission spectroscopy of Pt(diimine)(dithiolate) complexes has been studied in detail for selected systems. Unlike the solvatochromic absorption band, the emission band in these systems shows relatively little change in position with variation of solvent. The emission bands do, however, exhibit a significant decrease in emission intensity with increasing solvent polarity, corresponding to increased non-radiative decay as solvent polarity increases. From relative emission quantum yields and solution lifetimes by single photon counting, it is possible to calculate the natural radiative lifetimes of the complexes. Thus, for the $\mathrm{Pt}(\mathrm{Ph} 2 \mathrm{phen})(\mathrm{ecda})$ complex $2 \mathrm{e}, \tau_{\mathrm{o}}$ was determined to be $7.9 \mu \mathrm{sec}$.

A striking difference between the emission spectra of mnt and ecda complexes is that emission from mnt complexes shows a high degree of structure while that from ecda complexes are 
broad and asymmetric. The contrast in shape of emission bands between mnt and ecda complexes suggested a difference in excited state structure which was probed more fully by examining the temperature dependence of emission in rigid glasses down to $6 \mathrm{~K} .^{7}$ For mnt complexes the emission energy did not change upon going from fluid solution to rigid glass. Between $165 \mathrm{~K}$ (the glassing temperature of the solvent mixture) and $6 \mathrm{~K}$ there was an increase in emission intensity with decreasing temperature accompanied by sharpening of the vibrational structure. The emission lifetimes showed good first order decay consistent with the emission originating from a single excited state. On the other hand, the emission spectra of the ecda complexes $\mathrm{Pt}\left(\mathrm{Me}_{2}\right.$ bpy)(ecda) and $\mathrm{Pt}\left(\mathrm{Ph}_{2}\right.$ phen)(ecda) showed a rigidochromic shift of $1540 \mathrm{~cm}^{-1}$ between $175 \mathrm{~K}$ and $165 \mathrm{~K}$ and new bands emerging below $140 \mathrm{~K}$, as seen in Figure 1 for $\mathrm{Pt}\left(\mathrm{Ph}_{2} \mathrm{phen}\right)(\mathrm{ecda})$. The original emission band as well as the new ones increase in intensity down to $80 \mathrm{~K}$. When the temperature is reduced further (below $50 \mathrm{~K}$ ), the original emission band exhibits a sharp decrease in emission intensity, while the new bands remain relatively unchanged. This is illustrated in Figure 2 for $\mathrm{Pt}\left(\mathrm{Me}_{2} \mathrm{bpy}\right)(\mathrm{ecda})$ and clearly indicates the existence of multiple emitting states. This notion was supported by excitation spectra for $\mathrm{Pt}\left(\mathrm{Me}_{2}\right.$ bpy)(ecda) and $\mathrm{Pt}\left(\mathrm{Ph}_{2} \mathrm{phen}\right)(\mathrm{ecda})$ which differed depending on the wavelength $\lambda_{\mathrm{em}}$ at which the emission was followed.

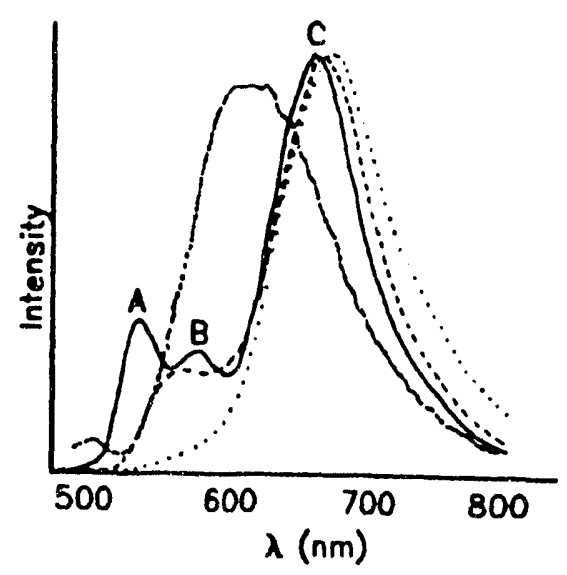

Figure 1. Emission spectrum of $\mathrm{Pt}\left(\mathrm{Ph}_{2}\right.$ phen)(ecda) in DMM at (--) $298 \mathrm{~K},(\cdots) 165 \mathrm{~K}$, $(--) 140 \mathrm{~K}$ and (-) $80 \mathrm{~K}$. 


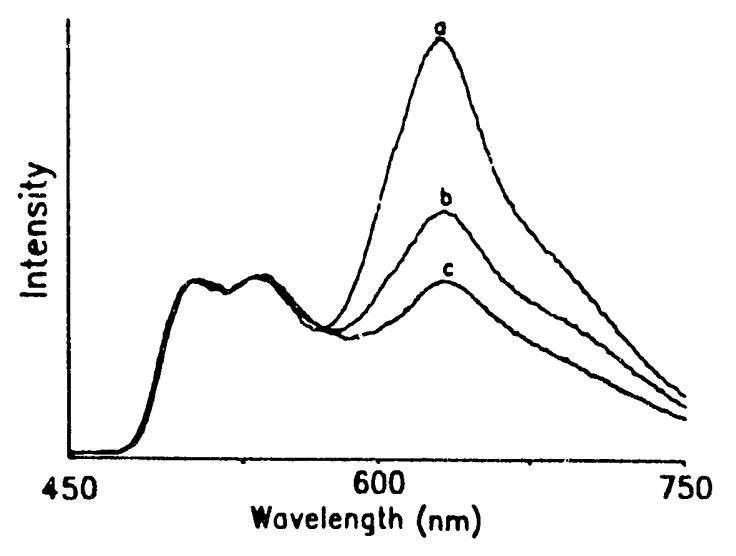

Figure 2. Emission spectrum of $\mathrm{Pt}\left(\mathrm{Me}_{2} \mathrm{bpy}\right)(\mathrm{ecda})$ in $\mathrm{DMM}$ at (a) $25 \mathrm{~K}$, (b) $10 \mathrm{~K}$, (c) $6 \mathrm{~K}$.

Lifetime studies of the two new emission bands at low temperature showed them to have an identical and relatively long lifetime, whereas the original emission band possessed a much shorter lifetime. For all three bands, the lifetime increased with decreasing temperature, as anticipated. The fact that the lifetime of the original band became longer with lower temperature whereas the quantum yield for emission decreased, gave evidence that more than one excited state was responsible for the original emission band. The excited state model employed in our analysis is similar to one developed by Crosby ${ }^{8}$ for $\mathrm{Ru}(\mathrm{bpy})_{3}{ }^{2+}$ and is shown in Figure 3. State 1 corresponds to an intraligand ${ }^{3}\left(\pi \pi^{*}\right)$ diimine based state and gives rise to the two new emission bands which are separated by only $1500 \mathrm{~cm}^{-1}$, whereas states 2 and 3 correspond to spin-orb: split components of a metal-to-ligand charge transfer (MLCT) thereby accounting for the unusual temperature dependence of the original emission band. The expressions for the lifetime and quantum yield based on this model are published and we have obtained an excellent fit from a nonlinear regression analysis of the model. The values of the decay rate constants and energy separations for the two emitting states (for $\mathrm{Pt}\left(\mathrm{Me}_{2} \mathrm{pby}\right.$ )(ecda): $\mathrm{k}_{2 \mathrm{r}}=6.16 \times 10^{5} \mathrm{~s}^{-1} ; \mathrm{k}_{3 \mathrm{r}}=4.39-4.4$ $\times 10^{5} \mathrm{~s}^{-1} ; \Delta \mathrm{E}=54.2 \mathrm{~cm}^{-1} ;$ for $\mathrm{Pt}\left(\mathrm{Ph}_{2}\right.$ phen $)($ ecda $) \mathrm{k}_{2 \mathrm{r}}=9.95 \times 10^{5} \mathrm{~s}^{-1} ; \mathrm{k}_{3 \mathrm{r}}=1.28-4.4 \times 10^{6} \mathrm{~s}^{-1}$; 
$\Delta \mathrm{E}=52.5 \mathrm{~cm}^{-1}$ ) are within the range expected for radiative rate constants and splittings of spinorbit terms for a complex of a third row $\mathrm{d}^{8}$ metal center. ${ }^{8}$ Consistent with the assignment of the two bands which emerged below $140 \mathrm{~K}$ as a ${ }^{3}\left(\pi \pi^{*}\right)$ diirnine based state, the radiative rate constant $\mathrm{k}_{\mathrm{r}}$ for those bands was calculated to be $3.2 \times 10^{3} \mathrm{sec}^{-1}$.

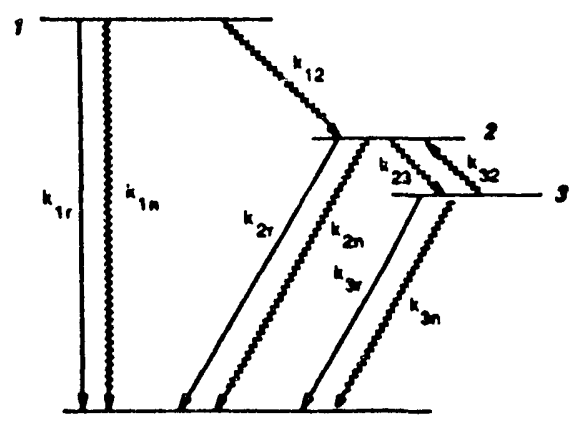

Figure 3. Excited state model for the emission of Pt(diimine)(ecda) complexes.

The $\mathrm{Pt}($ diimine)(S-S) complexes where S-S is a saturated dithiolate chelate or bis(thiolate) ligands showed remarkably similar properties to the ecda systems in their low temperature emission spectra, that is, their emission intensity decreased but their emission lifetime increased as the temperature was lowered from 50 to $6 \mathrm{~K}$. These results indicate that the emission in these complexes also originates from more than one excited state. One notable difference, however, between these complexes and the ecda systems is that the high energy emission from a $\pi-\pi^{*}$ diimine based excited state is not seen for these complexes.

Electronic Structural Calculations. In order to probe the electronic nature of the solvatochromic transitions and the emissive states, extended Hückel molecular orbital calculations were performed using the MOAN and CACAO programs developed by Mealli and Proserpio. ${ }^{9}$ The results are totally consistent with our spectroscopic data and a complete account of the calculations has been published. 10 The results show that for all of the diimine dithiolate and bis(thiolate) complexes examined, the lowest unoccupied MO is almost exclusively $\pi_{\text {diimine' }}^{*}$ whereas the highest occupied MO is a combination of $\mathrm{Pt}(\mathrm{d})$ and $\mathrm{S}(\mathrm{p})$ atomic orbitals as shown in 
Figure 4 for $\mathrm{Pt}\left(\mathrm{Me}_{2} \mathrm{bpy}\right)(\mathrm{mnt})$. The calculations thus indicate that the solvatochromic absorption is a $\operatorname{Pt}(\mathrm{d}) / \mathrm{S}(\mathrm{p})-\pi_{\text {diimine }}^{*}$ transition and that the emission is from a triplet state of the same orbital parentage. For the complexes containing a saturated diamine ligand, the nature of the HOMO changes very little from that of the diimine analogs, but the LUMO becomes exclusively $\pi^{*}$ dithiolate in character. This result agrees with the absence of a solvatochromic band in such saturated diamine systems and the observation of a blue shifted emission which involves the $\pi_{\text {dithiolate }}^{*}$ orbital and corresponds to a single emitting state. For the $\mathrm{Pt}($ diimine)(mnt) complexes which show a structured emission of single exponential decay, a $\pi_{\text {dithiolate }}^{*}$ orbital lies just above the $\pi_{\text {diimine }}^{*}$ LUMO. While this low lying empty $\pi_{\text {dithiolate }}^{*}$ orbital is slightly above the $\pi_{\text {diimine }}^{*}$ LUMO in the Hückel one electron approximation, we think that the triplet state in which it participates lies lower than the triplet state based on the LUMO, leading to a change in the emitting state for the mnt complexes. The similarity of the highly structured emissions from $\operatorname{Pt}($ diimine $)(m n t)$ and from $\operatorname{IrLL}(m n t)^{-}\left(L=L^{\prime}=C O, P(O R)_{3} ; L=C O, L^{\prime}=P A r_{3}\right)$ reported previously 2 support assignment of the emission of the $\mathrm{Pt}($ diimine $)(\mathrm{mnt})$ complexes as a ${ }^{3}\left(\mathrm{~d}-\pi_{\mathrm{mnt}}^{*}\right) \mathrm{MLCT}$ transition.
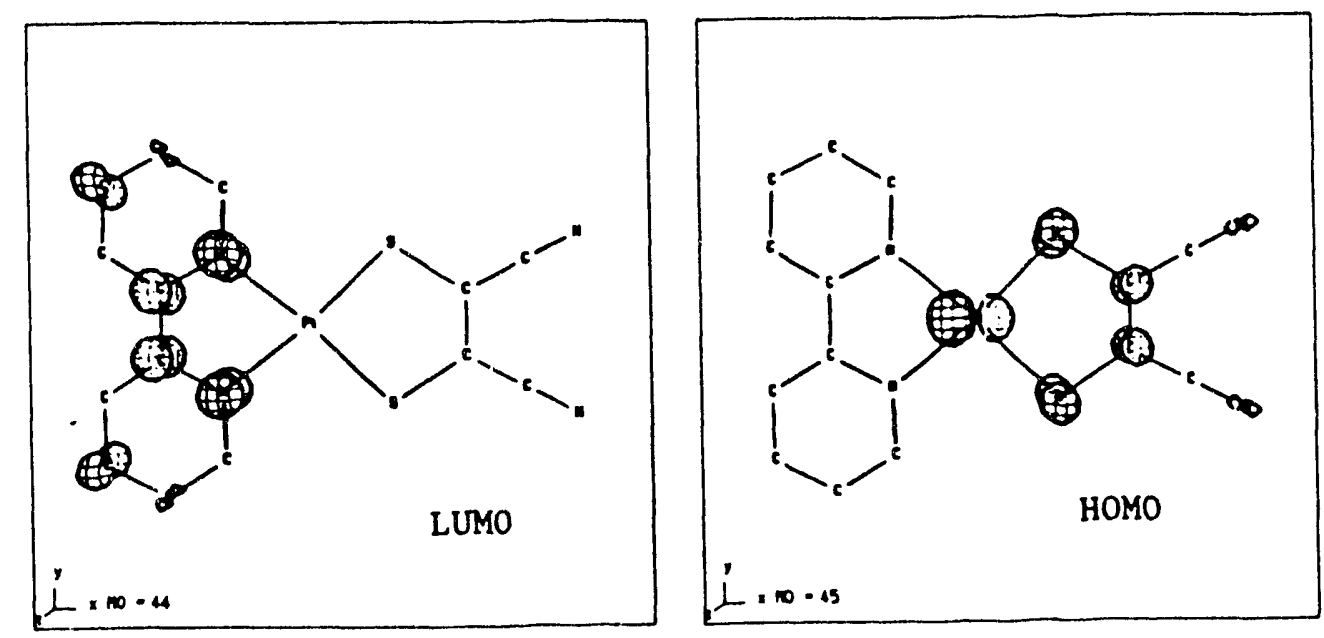

Figure 4. Molecular Orbital representation for HOMO and LUMO of Pt(bpy)(mnt).

Electron Transfer Quenching. In our initial studies of the photochemistry of Pt(diimine)(dithiolate) complexes, efforts concentrated on ecda derivatives because of their 
substantially greater solubility. In the presence of either the electron donor dimethylaniline (DMA) or the electron acceptor $o$-nitrobenzaldehyde (ONB), the emission of the complexes was quenched. Studies of the quenching of the $\mathrm{Me}_{2}$ bpy and $\mathrm{Ph}_{2}$ phen derivatives of $\mathbf{2}$ showed good Stern-Volmer behavior. In light of the fact that the lowest triplet excited states for DMA and ONB were well above the emission energy for the $\operatorname{Pt}($ diimine)(ecda) systems, it was evident that electron transfer quenching was occurring.

Based on the reversible reduction potentials for $\mathrm{Pt}\left(\mathrm{Me}_{2} \mathrm{bpy}\right)(\mathrm{ecda})(-1.28 \mathrm{v}$ vs $\mathrm{SCE})$ and $\mathrm{Pt}\left(\mathrm{Ph}_{2} \mathrm{phen}\right)(\mathrm{ecda})(-1.24 \mathrm{v})$ and their respective emission energies, it was possible to calculate a lower limit for the excited state reduction potential for the complexes as $0.74 \mathrm{v}$ and $0.83 \mathrm{v}$, respectively. To provide experimental confirmation of the values, fluorescence quenching studies using a graded series of ferrocene donors were conducted. Initial efforts, however, gave quenching rate constants which were too large because of quenching due to energy transfer as well as electron transfer. Additional studies based on lifetime quenching of $\mathrm{Pt}\left(\mathrm{Ph}_{2} \mathrm{Phen}\right)(\mathrm{ecda})$ have yielded results which are consistent with those of the fluorescence measurements. To date, the results have not provided an accurate independent estimate of that value. Additional quenchers having oxidation potentials greater than $0.7 \mathrm{v}$ remain to be examined.

Other Dithiolate Complexes. Complexes of $\mathrm{Pt}(\mathrm{II})$ containing ecda and other ligands in place of the diimine have been synthesized during the current contract period. Prior to the start of these studies, $\mathrm{Pt}(\mathrm{COD})(\mathrm{mnt})\left(\mathrm{COD}=1,5\right.$-cyclooctadiene) and $\mathrm{Pt}\left(\mathrm{P}(\mathrm{OEt})_{3}\right)_{2}(\mathrm{mnt})$ had been reported by us. ${ }^{2}$ The specific complexes which have been prepared are shown as 3 and have been characterized by NMR, IR and electronic spectroscopies. For the COD complexes $\mathrm{Pt}(\mathrm{COD})(\mathrm{mnt})$ and $\mathrm{Pt}(\mathrm{COD})(\mathrm{ecda})$ and for $\mathrm{Pt}(\mathrm{dppb})(\mathrm{mnt})$ (dppb = 1,2-bis(diphenylphosphino)benzene), single crystal structure determinations have been performed, confirming their square planar coordination geometries. ${ }^{11}$ 


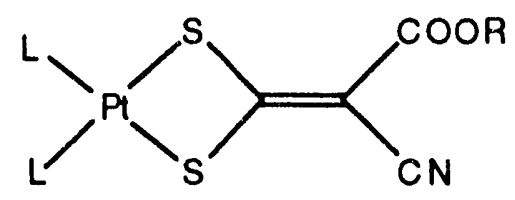

3

$$
\begin{aligned}
\mathrm{L}_{2}= & \text { (a) }\left(\mathrm{PR}_{3}\right)_{2} \quad\left(\mathrm{R}=\mathrm{Ph}, \mathrm{C}_{6} \mathrm{H}_{13}\right) \\
& \text { (b) }\left(\mathrm{P}(\mathrm{OR})_{3}\right)_{2}\left(\mathrm{R}=\mathrm{Ph}_{1} \mathrm{i}-\mathrm{Pr}\right) \\
& \text { (c) } \mathrm{Ph}_{2} \mathrm{PCH}_{2} \mathrm{CH}_{2} \mathrm{PPh}_{2} \text { (dppe) } \\
& \text { (d) } \mathrm{Ph}_{2} \mathrm{PCH}^{2} \mathrm{CH} \mathrm{PPh}_{2} \text { (dppv) } \\
& \text { (e) } \mathrm{O}-\mathrm{Ph}_{2} \mathrm{PC}_{6} \mathrm{H}_{4} \mathrm{PPh}_{2} \text { (dppb) } \\
& \text { (f) } 1,5 \text {-cyclooctadiene (COD) }
\end{aligned}
$$

In all cases, the complexes are emissive in rigid media at $77 \mathrm{~K}$. They do not, however, show luminescence in fluid solution nor do they exhibit the solvatochromic band characteristic of the diimine systems 1 and 2 . The emission maxima from $\mathbf{3}$ are highly blue shifted relative to the $\mathrm{Pt}$ (diimine)(ecda) complexes, and as with the diimine systems, there exists a striking difference between the emission spectra of $m n t$ and ecda derivatives. This is illustrated in Figure 5 for COD
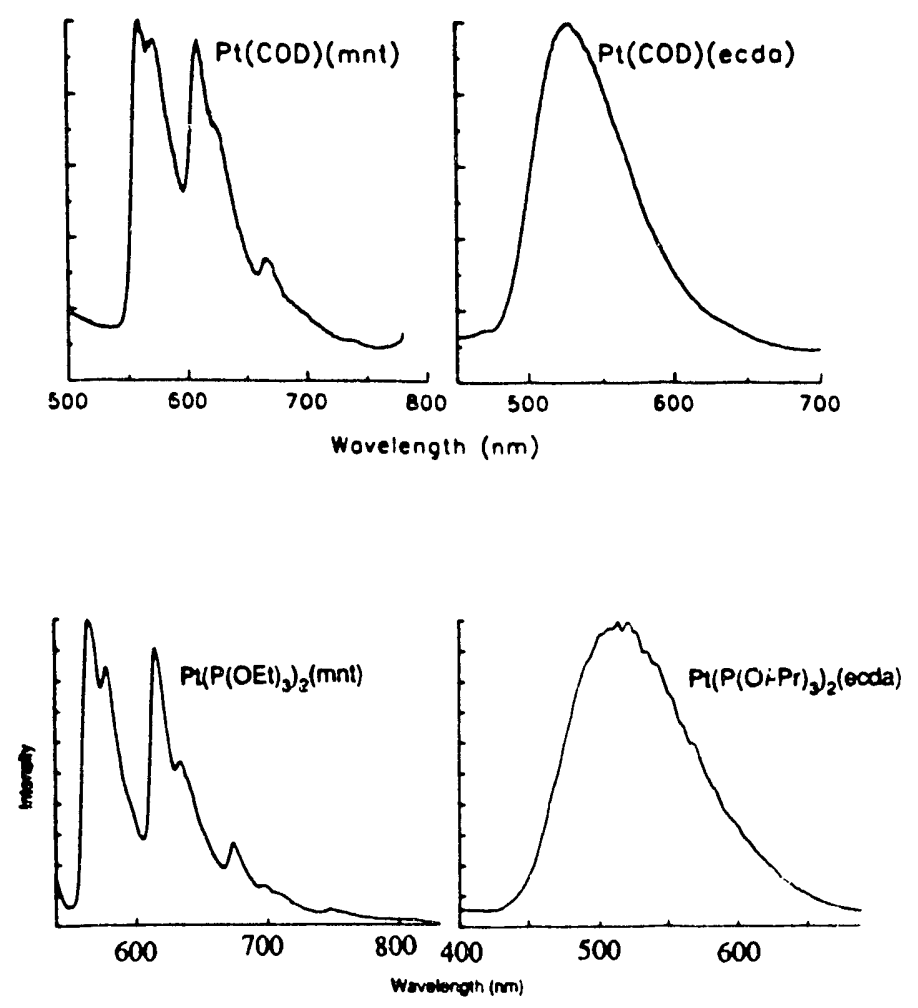

Figure 5. Low temperature emission from $\mathrm{Pt}(\mathrm{L}-\mathrm{L})(\mathrm{S}-\mathrm{S})$ complexes in $\mathrm{KBr}$ matrix at $77 \mathrm{~K}$. 
and phosphite complexes. The emission from the mnt systems is highly structured while that from the ecda derivatives is broad and asymmetric. All of these results are consistent with the electronic structural picture of these complexes which has been developed based on molecular orbital calculations and the experimental facts. For all of the complexes 3 , the LUMO is $\pi_{\text {dithiolate }}^{*}$ rather than the diimine based LUMO of 1 and 2 , resulting in the absence of a solventsensitive inter-ligand charge transfer transition. The blue shift of the emission for the ecda complexes 3 relative to that of 1 is explained by the energetically higher position of $\pi_{\text {dithiolate }}^{*}$ relative to the $\pi_{\text {diimine }}^{*}$ LUMO in 1 , and the difference in appearance of the emission brnds between the ecda and mnt derivatives is totally consistent with electronic structural differences between the two dithiolate chelates. All of the ecda and mnt complexes 3 thus possess an emitting state of ${ }^{3}\left(\operatorname{Pt}(d) / S(p)-\pi_{\text {dithiolate }}^{*}\right)$.

Another complex synthesized during the course of our studies is $\mathrm{Pt}(\mathrm{ecda})_{2}{ }^{2-} .12$ In contrast with $\mathrm{Pt}(\mathrm{mnt}) 2^{2-}$ originally synthesized in $1964,13 \mathrm{Pt}(\mathrm{ecda}) 2^{2-}$ is brightly emissive at $77 \mathrm{~K}\left(\phi_{\mathrm{em}}=\right.$ 0.62). Emission from $\mathrm{Pt}(\mathrm{mnt}) 2^{2-}$ has only been seen at $4 \mathrm{~K}$ by Gliemann ${ }^{14}$ and it appears rather weak, although structured as is seen for all of the mnt complexes. The $\mathrm{Pt}(\mathrm{ecda})_{2}{ }^{2-}$ complex shows an unusual shift of $10 \mathrm{~nm}$ in both absorption and emission maxima depending on the counter-ion $\left(\mathrm{n}-\mathrm{Bu}_{4} \mathrm{~N}^{+}(\mathrm{TBA})\right.$ and $\left.\mathrm{N}\left(\mathrm{PPh}_{3}\right)_{2}{ }^{+}(\mathrm{PPN})\right)$, indicating some small degree of ion-pairing in $\mathrm{CHCl}_{3}$. Upon photolysis with $310<\lambda<370 \mathrm{~nm}$ in $\mathrm{CH}_{2} \mathrm{Cl}_{2}$ or $\mathrm{CHCl}_{3}, \mathrm{Pt}(\text { ecda })_{2}{ }^{2-}$ undergoes rapid reaction, presumably via charge transfer to solvent (CTTS) excitation. The photochemical reaction does not occur with $\lambda>370 \mathrm{~nm}$ although light of this wavelength will yield the $500 \mathrm{~nm}$ emission at $77 \mathrm{~K}$. The photoreaction, which is a clean oxidation as seen in Figure 6, thus does not arise from the lowest excited state of the anionic complex. Photoreaction of this type has been seen previously by Vogler and Dooley. 15 


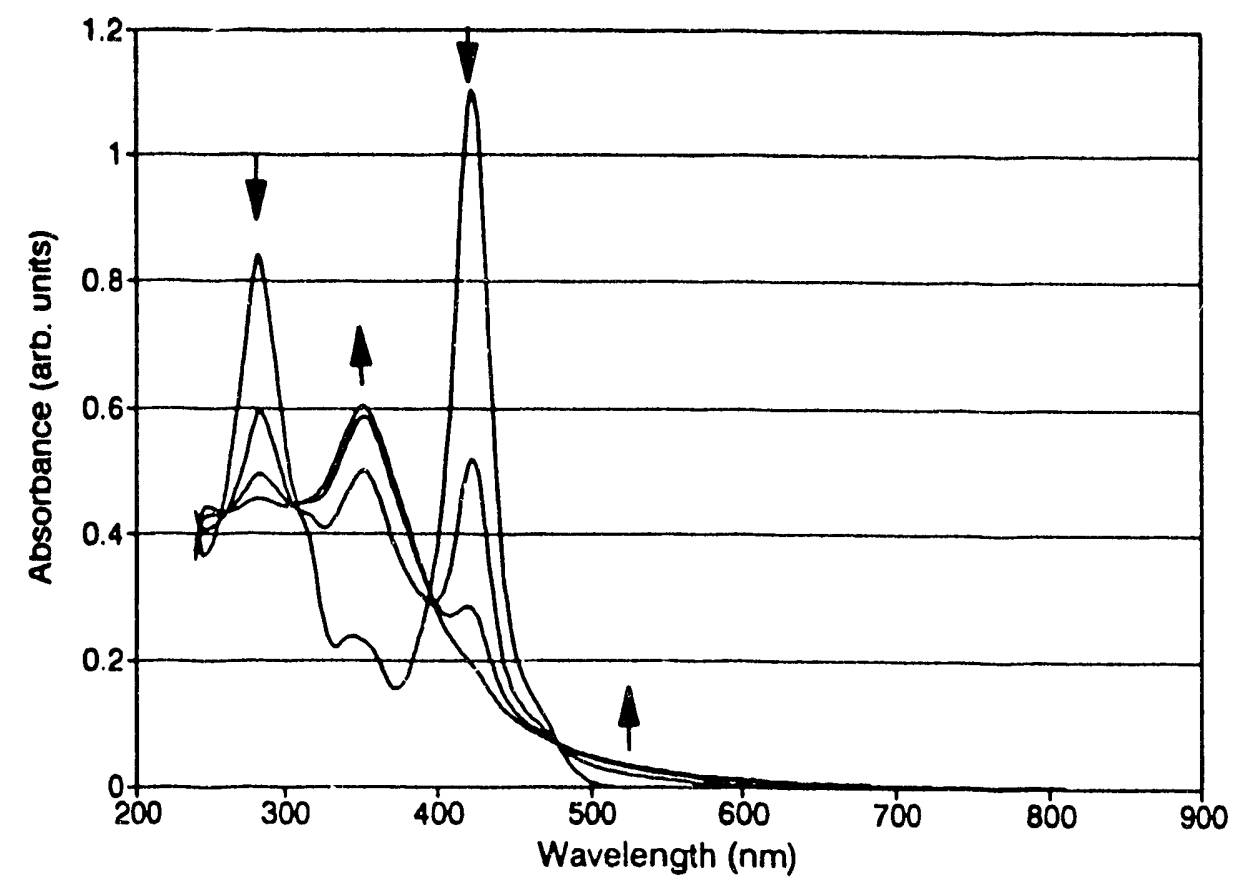

Figure 6. Photolysis $(\lambda>300 \mathrm{~nm})$ of $\mathrm{TBA}_{2}\left[\mathrm{Pt}(\text { ecda })_{2}\right]$ in $\mathrm{CHCl}_{3}$. Spectra taken at $0,30,60$, $90 \mathrm{~min}$.

Complexes of two other dithiolate ligands are under current investigation. The first of these ligands is maleic acid ester dithiolate (maed) which differs from mnt by having -COOMe substituents in place of $-\mathrm{CN}$. We expect maed complexes of $\mathrm{Pt}(\mathrm{II})$ to have much greater solubility than those of mnt without changing the electronic structure of the complex significantly. It is anticipated that $\mathrm{Pt}$ (diimine)(maed) complexes will have structured emissions and a solvatochromic interligand charge transfer. The synthesis of maed complexes will allow us to do solution studies of complexes with a 1,2-dithiolate ligand which because of solubility limitations of mnt complexes have only been performed with ecda systems to date.

The other ligand is quinoxolinedithiolate (qdt). The complex $\mathrm{Pt}\left(\mathrm{Me}_{4} \mathrm{phen}\right)(\mathrm{qdt}), 4$, has been prepared, and it exhibits the expected solvatochromism and solution emissive behavior. One aspect of the spectroscopy which has stimulated additional interest is the fact that both absorption and emission bands are sensitive to $\mathrm{pH}$ through proton binding at the quinoxoline nitrogen, as shown in Figure 7. Complexes based on these and other dithiolates are discussed more fully in the accompanying research proposal. 


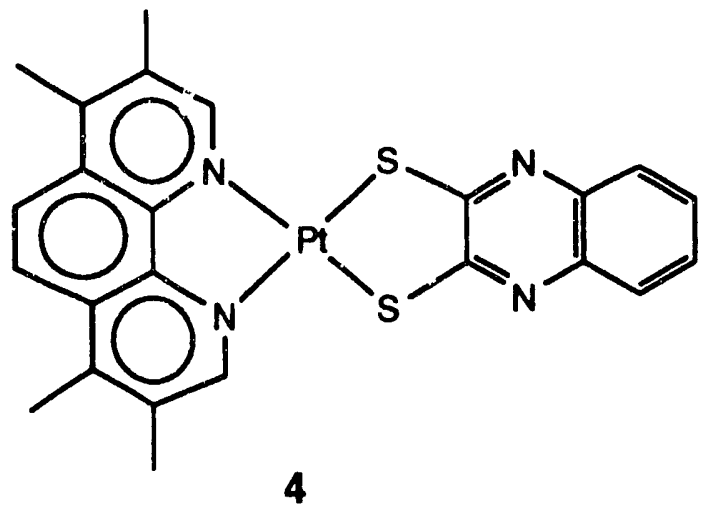

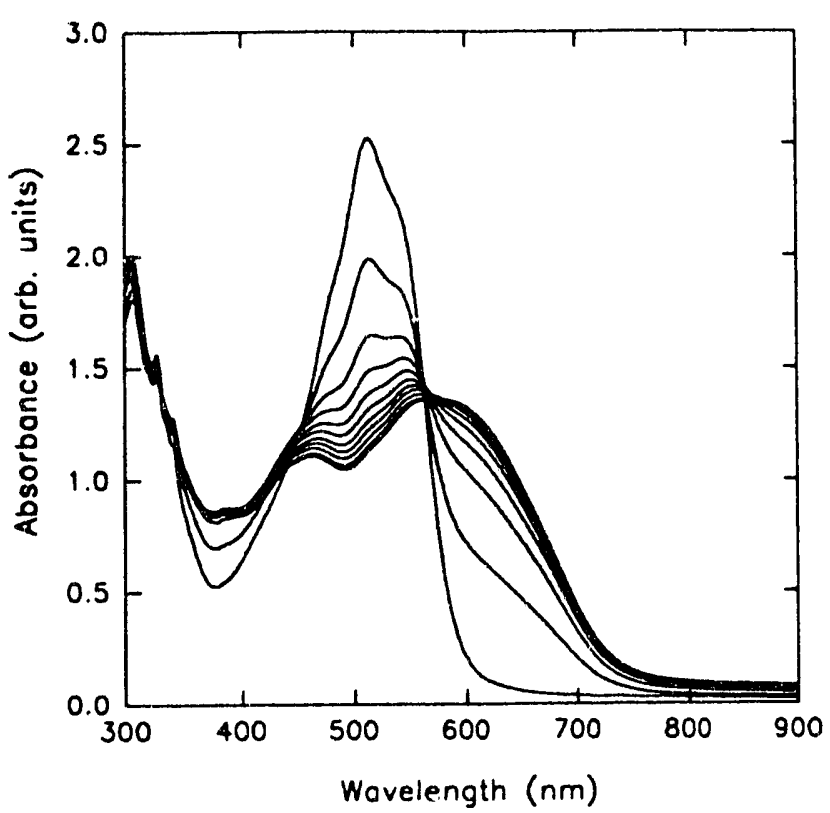

(a)

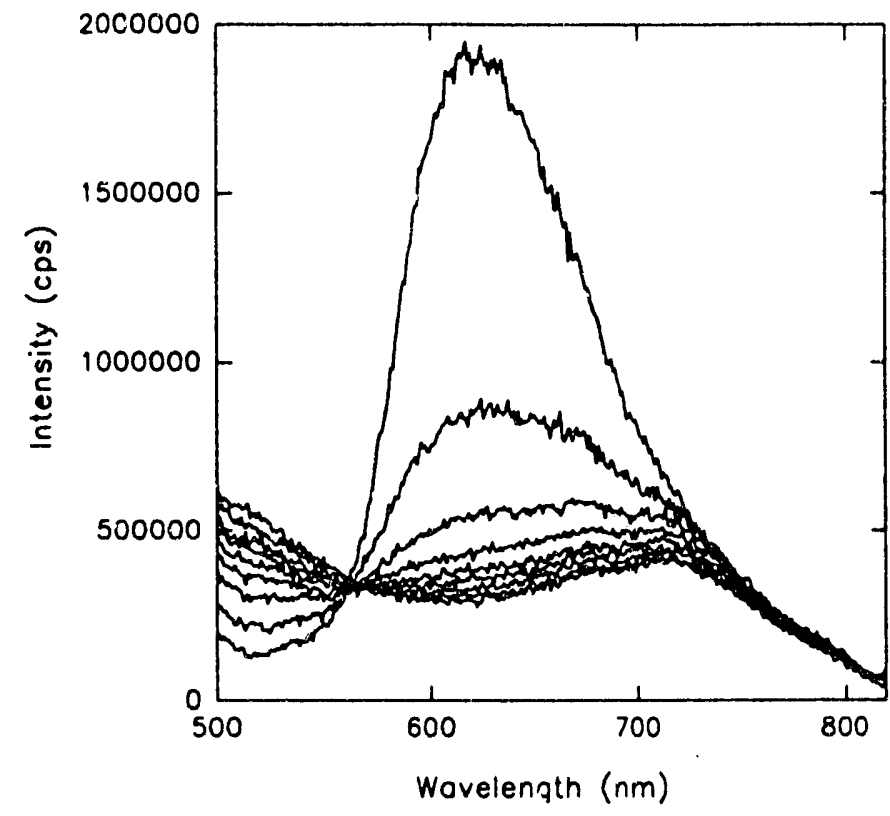

(b)

Figure 7. Absorption (a) and emission (b) spectra of $\mathrm{Pt}\left(\mathrm{Me}_{4}\right.$ phen)(qdt) in $\mathrm{MeOH}$ with $\mathrm{CH}_{3} \mathrm{COOH}$ concentrations of $0,1.13,2.27,3.40,4.53,5.67,6.80,7.93,9.07$, $10.20,11.33 \mathrm{mM}$. 
Luminescent Alkyl Carbonyl Complexes. Prior to the current contract, we had reported the synthesis and characterization of an unusual series of alkyl carbonyl complexes exemplified by 5 which were emissive in fluid solution. ${ }^{3}$ Despite the presence of the carbonyl ligand, the complexes were seen to react upon photolysis in a manner consistent with metal-alkyl bond homolysis. Efforts during the past year have confirmed the homolytic mode of reactivity and are designed to show that the very efficient $\beta$-elimination given in eq. (1) takes place by $M-R$ scission to generate a radical pair followed rapidly by $\beta$-hydrogen atom transfer. Other studies

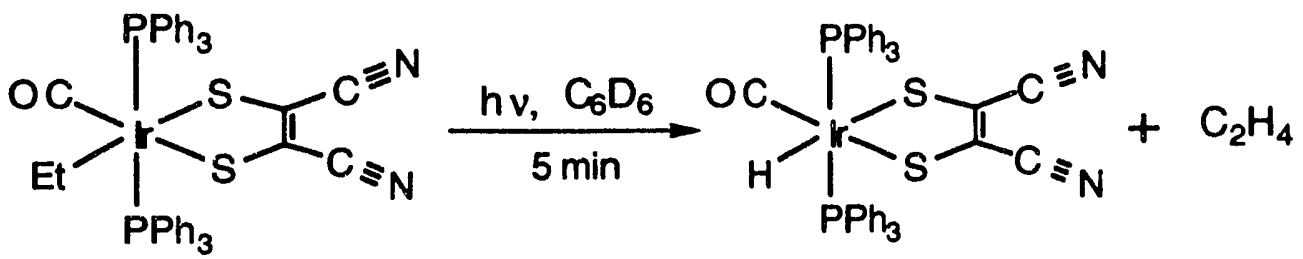

5

during the year on the chemistry of $\mathbf{5}$ have led to structural characterization of the square pyramidal acyl complex $\operatorname{Ir}(\mathrm{COEt})\left(\mathrm{PPh}_{3}\right)_{2}$ (mnt) formed by $\mathrm{CO}$ insertion into the metal-alkyl bond as shown in Figure 8 and determination of the kinetic parameters for the migratory insertion process. 16

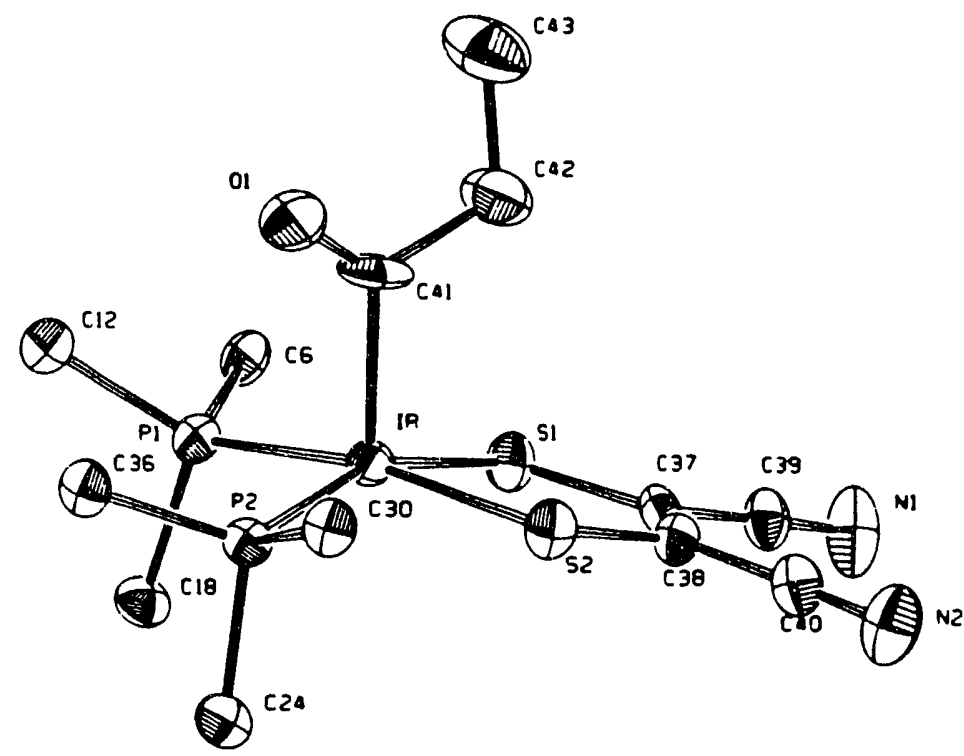

Figure 8. A perspective view of the molecular structure of $\operatorname{Ir}(\mathrm{COEt})\left(\mathrm{PPh}_{3}\right)_{2}(\mathrm{mnt})$. 


\section{References and Footnotes}

1. Zuleta, J. A.; Chesta, C. A.; Eisenberg, R. J. Am. Chem. Soc. 1989, 111, 8916.

2. (a) Johnson, C. E.; Eisenberg, R.; Evans, T. R.; Burberry, M. S. J. Am. Chem. Soc. 1983, 105, 1795. (b) Megehee, E. G.; Johnson, C. E.; Eisenberg, R. Inorg. Chem. 1989, $28,2423$.

3. Bradley, P.; Johnson, C. E.; Eisenberg, R. J. Chem. Soc., Chem. Commun. 1988, 255.

4. (a) Manuta, D. M.; Lees, A. J. Inorg. Chem. 1983, 22, 3825. (b) Dong, D. C.; Winnik, M. A. Photochem. Photobiol. 1982, 35, 17.

5. (a) Miller, T. R.; Dance, G. J. Am. Chem. Soc. 1973, 95, 6790. (b) Vogler, A.; Kunkely, H.; Hlavatsch, J.; Merz, A. Inorg. Chem. 1984, 23, 506. (c) Koester, V. J. Chem. Phys. Lett. 1975, 32, 575; Truesdell, K. A.; Crosby, G. A. J. Am. Chem. Soc. 1985, 107, 1788. (d) Highland, R. G.; Crosby, G. A. Chem. Phys. Lett. 1985, 119, 454. (e) Highland, R. G.; Brummer, J. G.; Crosby, G. A. J. Phys. Chem. 1986, 90, 1593. (f) Crosby, G. A.; Highland, R. G.; Truesdell, K. A. Coord. Chem. Rev. 1990, 8916.

6. (a) Prasad, P. R.; Williams, D. J. "Introduction to Nonlinear Optical Effects in Molecules and Polymers," John Wiley and Sons, New York, 1991. (b) Williams. D. J., ed. "Nonlinear Optical Properties of Organic and Polymeric Materials," ACS Symposium Series, 1983, 233. (c) Tweig, R. J.; Jain, K. in (b), p. 57.

7. Zuleta, J. A.; Bevilacqua, J. M.; Rehm, J. M.; Eisenberg, R. Inorg. Chem. 1992, 31, 1332.

8. Hager, C. D.; Crosby, G. A. J. Am. Chem. Soc. 1975, 97, 7031.

9. Mealli, C.; Proserpio, D. J. Chem Ed., 1990, 67, 399.

10. Zuleta, J. A.; Bevilacqua, J. M.; Proserpio, D. M.; Harvey, P. D.; Eisenberg, R. Inorg. Chem. 1992, 31, 2396. 
11. (a) Bevilacqua, J. M.; Zuleta, J. A.; Eisenberg, R. Inorg. Chem. 1992, submitted for publication. (b) Bevilacqua, J. M.; Zuleta, J. A.; Eisenberg, R. Organometallics 1992, to be submitted.

12. Cummings, S.; Eisenberg, R. (manuscript in preparation).

13. Gray, H. B.; Williams, R.; Bernal, I.; Billig, E. J. Am. Chem. Soc. 1962, 84, 4756.

14. Günter, W.; Gliemann, G.; Klement, U.; Zabel, M. Inorg. Chim. Acta 1989, 51.

15. (a) Vogler, A.; Kunkely, H. Inorg. Chem. 1982, 21, 1172. (b) Dooley, D. M.; Patterson, B. M. Inorg. Chem. 1982, 21, 4330.

16. Suardi, G.; Bradley, P. B.; Eisenberg, R. Organometallics 1992, to be submitted. 


\section{DOE-SUPPORTED PUBLICATIONS (1990-1993)}

Platinum(II) Diimine Dithiolates. New Solution Luminescent Complexes, Zuleta, J. A.; Burberry, M. S.; Eisenberg, R. Coord. Chem. Rev. 1990, 97, 47.

Solvatochromic and Emissive Properties of Pt(II) Complexes with 1,1- and 1,2-Dithiolates, Zuleta, J. A.; Bevilacqua, J. M.; Eisenberg, R. Coord. Chem. Rev. 1992, 111, 237.

Multiple State Emission from Platinum(II) Diimine Dithiolate Complexes. Solvent and Temperature Effects, Zuleta, J. A.; Rehm, J. M.; Bevilacqua, J. M.; Eisenberg, R. Inorg. Chem. $1992,31,1332$.

Spectroscopic and Theoretical Studies on the Nature of the Excited State in Diimine Dithiolate Complexes of Platinum(II), Zuleta, J. A.; Bevilacqua, J. M.; Proserpio, D. M.; Harvey, P. D.; Eisenberg, R. Inorg. Chem. 1992, 31, 2396.

(Cyclooctadiene)platinum Dithiolate Complexes. Synthesis, Characterization and Emissive Properties, Bevilacqua, J. M.; Zuleta, J. A.; Eisenberg, R. Organometallics 1992, submitted for publication.

Platinum(II) Dithiolate Complexes with Phosphine Ligands. Synthesis, Characterization and Emissive Properties, Bevilacqua, J. M.; Zuleta, J. A.; Eisenberg, R. Inorg. Chem. 1992, to be submitted.

The Luminescence and Photochemistry of Bis(dithiolato)platinum(II) Complexes, Cummings, S. D.; Eisenberg, R. Inorg. Chem. 1992, to be submitted.

Migratory Insertion in Alkyl Carbonyl Dithiolate Complexes of Iridium, Suardi, G.; Bradley, P. B.; Eisenberg, R. Organometallics, 1992, to be submitted.

Solution Emissive Complexes of Platinum(II) Containing Quinoxoline Dithiolate. pH Dependent Emission and Absorption, Cummings, S. D.; Eisenberg, R., manuscript in preparation. 

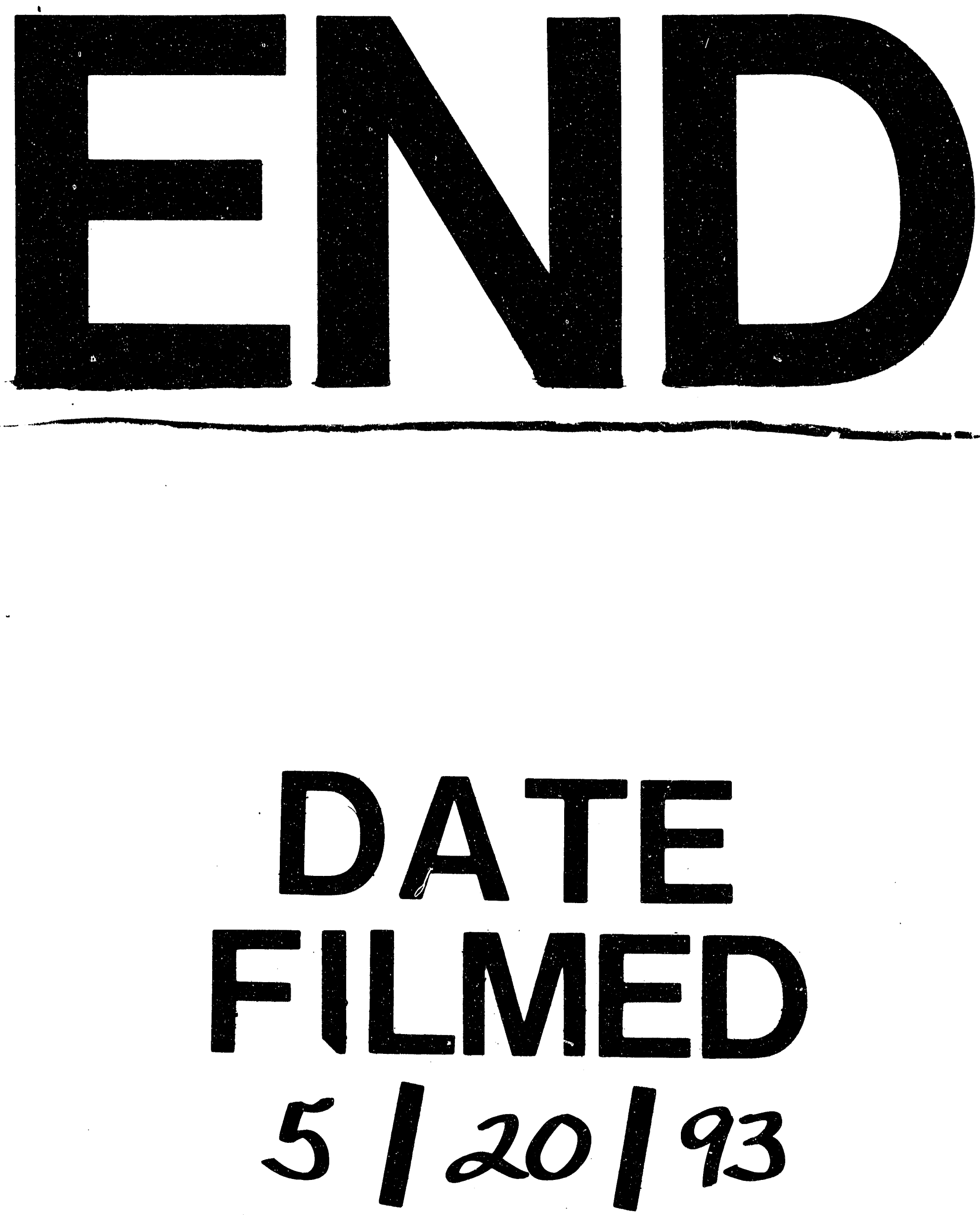
